Egyptian

Orthodontic Journal

\title{
ATOMIC FORCE MICROSCOPIC EVALUATION OF LIGHT-CURED FILLED SEALANT (PRO SEAL) EFFICACY IN PREVENTING ENAMEL DEMINERALIZATION IN ORTHODONTIC PATIENTS
}

\author{
* Suzi F. Shinaishin \\ ${ }^{* *}$ Safaa A. Ghobashy
}

ABSTRACT

White spot formation is an undesirable complication of orthodontic fixed appliances. It is due to enamel demineralization by organic acids resulted from accumulation of cariogenic bacteria around the brackets. This lesion can jeopardize the medical and esthetic benefits of orthodontic therapy. Pro Seal (a new highly filled light-cured resin) was claimed to protect the susceptible area adjacent to bonded attachment and require no patient compliance. Therefore, the purpose of this study was to investigate the efficacy of this new sealant in preventing enamel decalcification in vivo and compare its effect with varnish and unfilled sealant using Atomic force microscopy. Thirty two premolars with brackets on their buccal surfaces were classified according to treatment with different materials into four groups ( $n=8$ for each one, 4 maxillary and 4 mandibular); Control (non-treated), Fluoride varnish, Unfilled sealant and Filled sealant (Pro Seal). After two months the brackets were debonded and the teeth were extracted and prepared for investigation. Each sample was scanned twice at two different scan areas (50 and $10 \mu \mathrm{m}$ ) at the buccal cervical third of the crown. Images were recorded with slow scan rate; the mean roughness height and total surface area were calculated for each

\footnotetext{
*Assistant professor of Oral Biology, Faculty of Dentistry Ain Shams University.

** Assistant professor of Orthodontics, Faculty of Dentistry, Tanta University.
} 
Egyptian

Orthodontic Journal

scan area. Tapping mode images and statistical analysis showed that Pro Seal treated samples had the least damaged enamel surface of all groups and the lowest mean of roughness height and total surface area. In conclusion, Pro Seal was the most effective prophylaxis technique in preventing enamel deminerafization around orthodontic brackets.

\section{INTRODUCTION}

Enamel demineralization is an undesirable complication of orthodontic fixed appliance therapy, especially in patients with poor oral hygiene. This can jeopardize the medical and esthetic benefits of orthodontic therapy ${ }^{(1)}$. Placing of fixed orthodontic appliance alters the oral environment, causing both quantitative and qualitative changes in dental plaque ${ }^{(2)}$. The demineralization adjacent to brackets might be partly due to the rough, retentive and decalcified surface of enamel produced by acid etching and lack of sealant ${ }^{(3)}$. Demineralization has been reported in $50 \%$ of teeth treated with brackets and in up to $50 \%$ of patients ${ }^{(4-6)}$.

To optimize the results of orthodontic work, decalcification prophylaxis is particularly important during orthodontic treatment ${ }^{(7)}$. Many proposed strategies are consistent with measures of general caries prevention, such as patient motivation, nutritional counseling, plaque staining, professional tooth cleaning ${ }^{(8)}$, chlorhexidine use $^{(9)}$ and fluoridation ${ }^{(10,11)}$. It is widely accepted that fluoride exerts its anticariogenic properties by the formation of fluoroapatite in the outer enamel surface, resulting in a mineral with lower solubility in acid environment ${ }^{(12)}$. Reports suggest that topical fluoride applications in the form of toothpastes ${ }^{(11,13)}$, gels $^{(14)}$, rinses ${ }^{(5,11,13,15)}$, and fluoride varnishes ${ }^{(15)}$ might reduce or eliminate decalcification during fixed orthodontic treatment. However, the effectiveness of these products is directly related to the patient's compliance, resulting in only limited benefit ${ }^{(14,17)}$.

Researches and development have provided orthodontics with new materials that protect the susceptible area adjacent to bonded attachment, and require no patient compliance. One approach is to use glass ionomer cement ${ }^{(18,19)}$ for band cementation and bonding orthodontic brackets, another promising material is fluoride releasing resin ${ }^{(20-22)}$. However, there is a need for improvement in both glass ionomers and fluoride releasing resins before these products will gain wide acceptance in orthodontic bonding ${ }^{(23-26)}$. 
Application of resin sealant on the enamel surface around and beneath the orthodontic bracket was thought to provide several benefits ${ }^{(27,28)}$ : increased bond strength, sealing of etched enamel, and protection against demineralization around the brackets. The chemically cured sealants do not effectively seal smooth enamel surface, because of oxygen inhibition of polymerization ${ }^{(29-31)}$. On the other hand, light-cured sealants have been proven to cure completely on smooth enamel surface and prevent enamel demineralization effectively in vitro $(31,32)$. However, in vivo studies demonstrated that the light-cured unfilled resin could not provide more protection than the chemically cured sealant, as wearing off or breaks in the sealant layer might result in decalcification ${ }^{(33)}$.

Pro Seal, a new highly filled light-cured resin, was reported as a preventive method to reduce enamel demineralization in vitro. It was claimed, by the manufacturer, to protect enamel surface and withstand mechanical (tooth brushing) and chemical (acid attack) wearing ${ }^{(3)}$.

Pro Seal was not supposed to have a negative influence on shear-peel bond strength in vitro. Statistical evaluation showed no significant change in shearpeel bond strength either when Pro Seal was used in addition, or when that fluoride-releasing, light-curing sealant was substituted for the bonding agent ${ }^{(34,35)}$.

Therefore, the purpose of this study was to investigate the efficacy of Pro Seal in preventing decalcification in vivo using Atomic force microscopy (AFM) and compare its effect with fluoride varnish and un-filled sealant.

\section{Material \& Methods}

Eight young patients (13-15 years) from the Postgraduate Orthodontic Clinic at Tanta University were selected for the present study. All patients required extraction of the first premolars for orthodontic treatment with fixed appliances. The premolars were free from cracks, caries or filling and have sufficient clinical crown length to allow bracket placement at the standardized position. The patients were instructed for precise oral hygiene.

\section{Tooth preparation and group allocation:}

The patients in this study were divided into 2 groups (A\& B) each comprised 4 patients with 16 premolars in four quadrants, the material application was performed as shown in (fig.1). This disposition allows the same environment for all the tested teeth, thus the collected teeth were divided into four subgroups each contained 8 premolars (4 maxillary and 4 mandibular). 


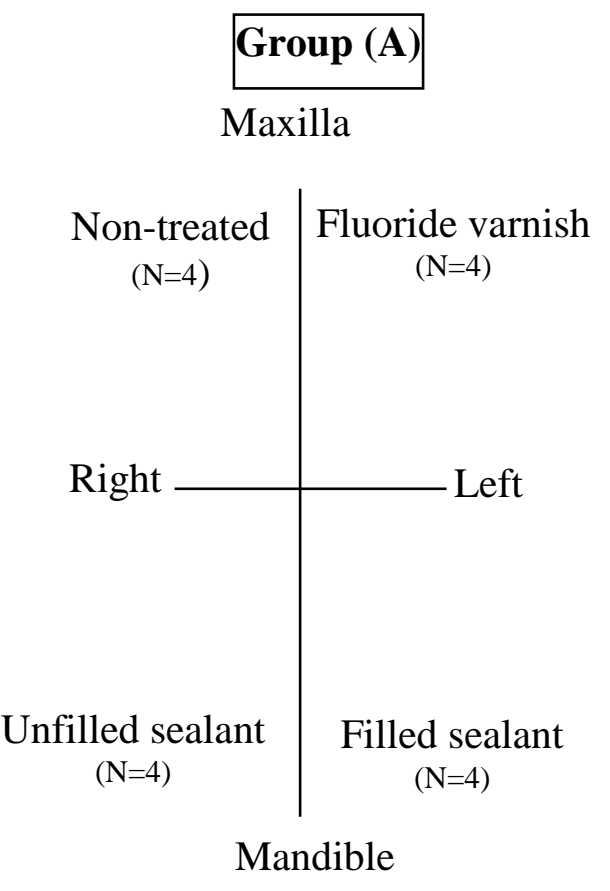

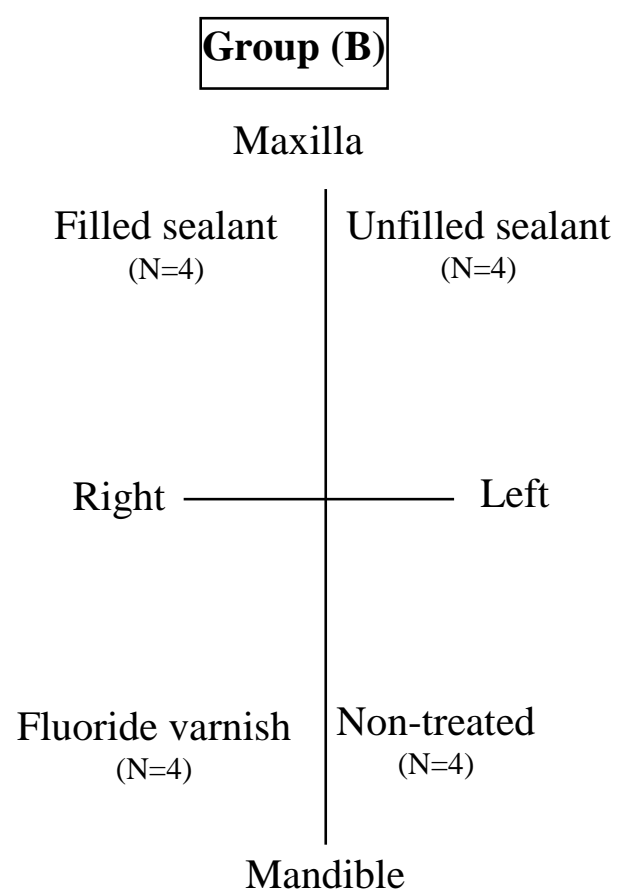

Maxilla

Fig. (1): Disposition of experimental materials.

The enamel surface of all teeth were polished with pumice for 10 seconds, sprayed with water and dried with compressed oil-free stream, and the materials were applied as follow:

\section{1- Control (non-treated):}

The enamel surface was etched for 30 seconds with $37 \%$ phosphoric acid gel at $4 \mathrm{~mm}$ from the buccal cusp tip and centered along the long axis of the tooth, sprayed with water for 30 seconds, and air dried thoroughly. The edgewise brackets were bonded with chemical cured unfilled resin according to the manufacturer instructions.

\section{2- Fluoride varnish:}

After bracket bonding (the same steps as in the non-treated group) the teeth were air dried and fluoride varnish was painted in a thin layer on the buccal surfaces surrounding the brackets and allowed to dry for 5 minutes. The patients 
were instructed to refrain from tooth brushing until the morning after the application.

\section{3- Unfilled sealant:}

The whole buccal surface was etched for 30 seconds with $37 \%$ phosphoric acid gel, sprayed with water for 60 seconds and air dried, the brackets were bonded. An unfilled light-cured sealant was applied in a thin, uniform layer on the etched enamel with a brush and then cured with a curing light for 20 seconds.

\section{4- Filled sealant:}

After etching and bracket bonding, (the same as in the unfilled group) a filled light-cured sealant (Pro Seal) was applied in a thin uniform layer on the etched enamel with brush and cured with the curing light for 20 seconds.

After 2 months, the brackets were debonded and the premolars were extracted. The roots and lingual parts of the crowns were cut off with a diamond disk on low-speed without contamination on the buccal surfaces, rinsed with distilled water and stored in water at $4 c \dot{\circ}$ until use.

The samples were rinsed ultrasonically in water for 10 minutes; excess water was removed gently with absorbing paper. Each specimen was mounted on the microscope stunt to be imaged at room temperature in an open air condition.

\section{Surface structure characterization:}

Tapping mode measurements were performed with an AFM (Auto probe CP-researcher, Thermo-microscope) in the National Institute for Standards (NIS). Each sample was scanned at two different scan areas (50 and $10 \mu \mathrm{m})$ at the cervical third of the crown. Images were recorded with slow scan rate and resolution of $512 \times 512$ pixels per image. The collected 3-D topographical data were analyzed using data analysis soft ware (SPM lab NT ver.5.01). The mean roughness height $(\mathrm{Ra})$ and the total surface area (SA) were measured for each scanned area, and numerical data were presented as means and standard deviation values. One way ANOVA and Post Hoc LSD tests were used to analyze the data.

\section{RESULTS}

\section{I- Surface topography:}

Examination of AFM images and revising the numerical data revealed no significant difference between the samples within the same subgroup with reference to location (maxillary and mandibular). 
Egyptian

Orthodontic Journal

\section{1- Non-treated group:}

AFM tapping mode images of 50x50 $\mu \mathrm{m}$ scanned area revealed that the enamel surface presented narrow perikymata grooves and flattened perikymata ridges with no evidence of rod ends. Cracks and destructed areas were detected in the surface (fig.2). The 3-D image showed high surface irregularity and focal deep areas corresponding to the cracks seen in the 2-D image (fig.3). The enamel exhibited defective crystals arrangement with spherical structures and wide inter-crystalline spaces (fig.4).

\section{2- Fluoride varnish group:}

The enamel surface presented wide perikymata grooves, non obvious perikymata ridges and localized areas of destruction (fig.5) and highly rough enamel surface in the 3-D image (fig.6). The images of 10x10 $\mu \mathrm{m}$ scan area revealed tightly packed crystals with focal destruction areas (fig.7).

\section{3- Unfilled sealant group:}

The enamel surface showed moderately wide but shallow perikymata grooves (fig.8). The surface appeared with moderate roughness in the 3-D image (fig.9). Tightly packed enamel crystals with minimal destructed areas in 10x10 $\mu \mathrm{m}$ image (fig.10).

\section{4- Filled sealant (Pro Seal) group:}

The enamel surface showed obvious perikymata grooves and perikymata ridges as wave-like parallel rings. The enamel surface appeared sound and exhibited localized depressions (focal holes) with no evidence of rod ends (fig.11). The 3-D image revealed relatively smooth enamel surface (fig.12). Images of $10 \times 10 \mu \mathrm{m}$ revealed the presence of conical depression (focal holes) surrounded by tightly arranged crystals (fig.13).

\section{II- Statistical analysis:}

The means and SD of the roughness height and total surface area of the scanned areas were represented in table $(1)$ and figure $(14,15)$. One way ANOVA test revealed that the mean and SD of $(\mathrm{Ra})$ and $(\mathrm{SA})$ of the control group were significantly higher than other groups while the Pro Seal group showed the least values. Highly significant difference $(\mathrm{p}<0.001)$ was registered between the experimental groups (tables 2-5). There was a significant positive correlation between roughness height and total surface area $(\mathrm{p}<0.001)$ in all groups (fig.16). 


\section{Egyptian \\ Orthodontic Journal}

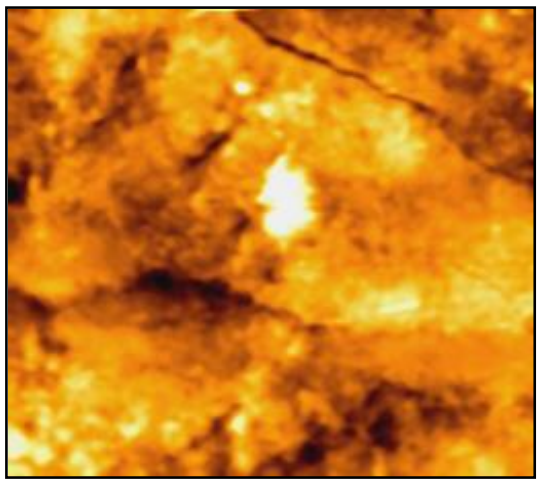

Fig.2: AFM image of non-treated enamel surface showing narrow grooves, cracks and many destructed areas $(50 \times 50 \mu \mathrm{m})$.

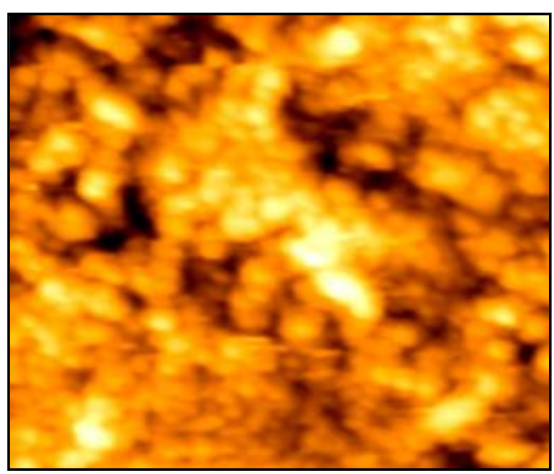

Fig.4: Defective crystal arrangement with many spherical structures of non- treated enamel surface. $(10 \times 10 \mu \mathrm{m})$

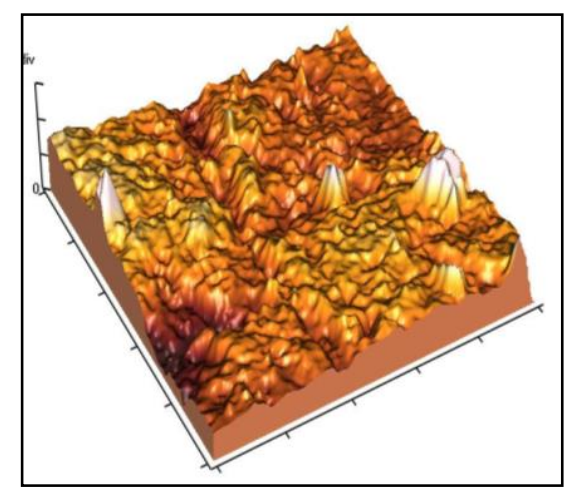

Fig.6:. 3-D image showing highly rough enamel surface with wide perikymata grooves.

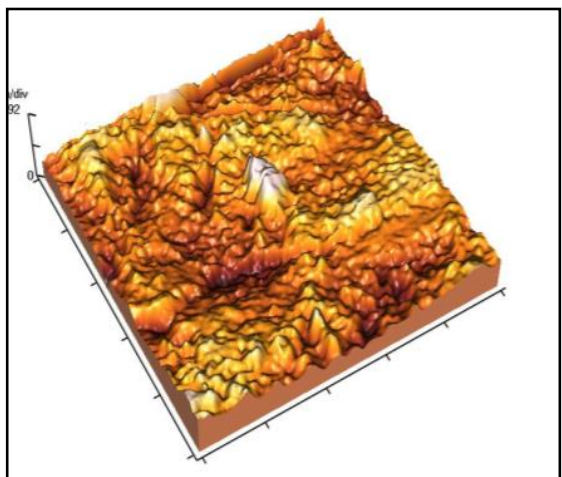

Fig. 3: 3-D image showing high surface irregularity with localized deep areas.

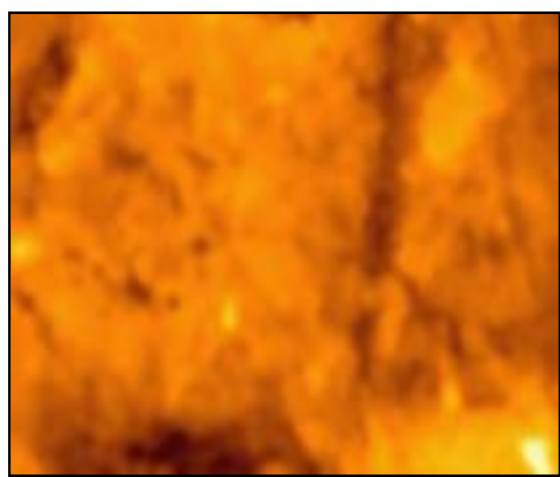

Fig.5: Enamel surface of varnish group with moderately wide perikymata groove and minute areas of destruction $(50 \times 50 \mu \mathrm{m})$.

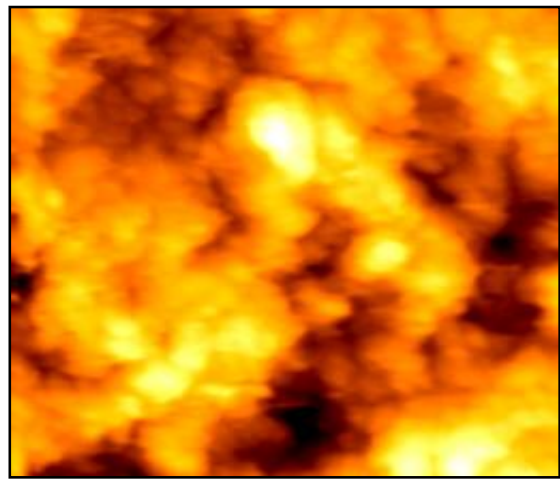

Fig.7: Areas of focal destruction within tightly packed crystals in varnish group $(10 \times 10 \mu \mathrm{m})$. 


\section{Egyptian}

Orthodontic Journal

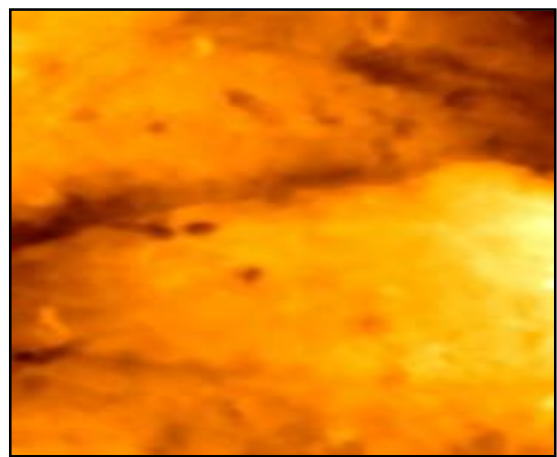

Fig.8: AFM image of unfilled sealant group presented wide perikymat grooves and flattened perikymata ridge $(50 \times 50 \mu \mathrm{m})$.

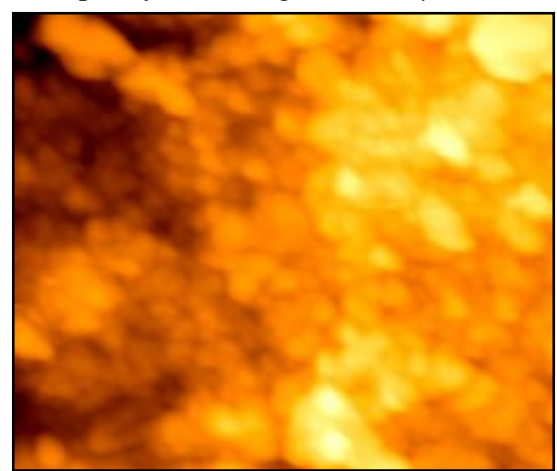

Fig.10: Tightly packed enamel crystals of unfilled sealant group. $(10 \times 10 \mu \mathrm{m})$,

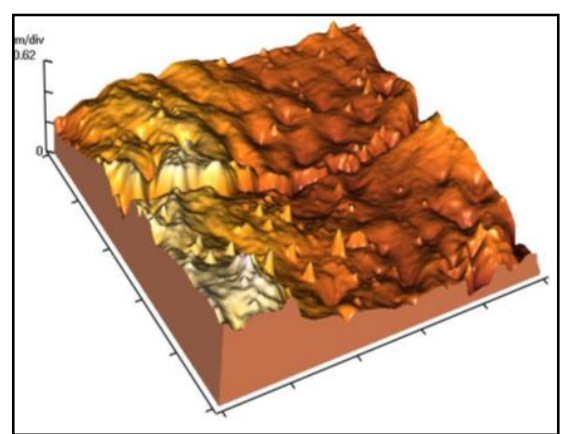

Fig.12: 3-D image showing relatively smooth enamel surface between the focal holes.

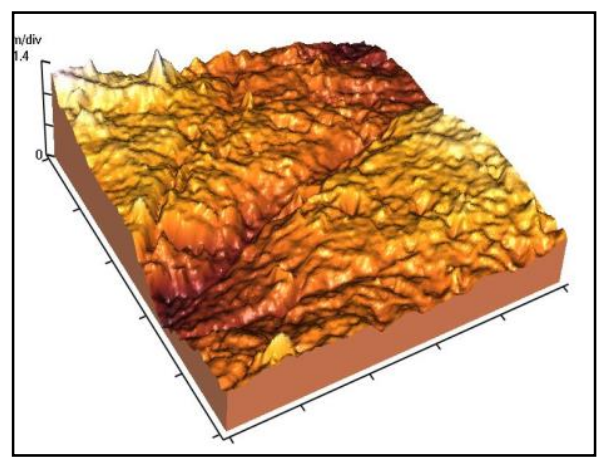

Fig.9: 3-D image showing moderately rough enamel surface and wide perikymata groove.

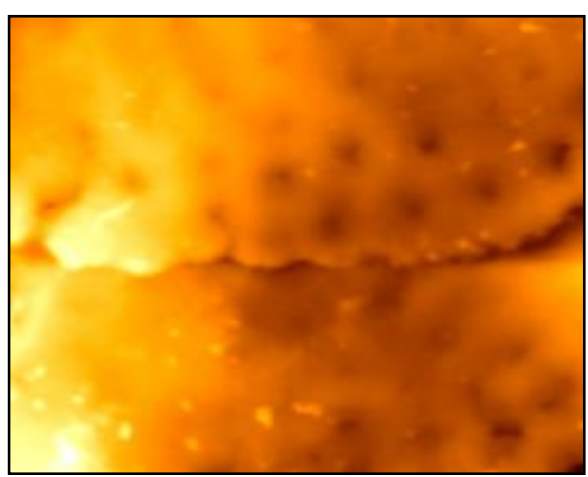

Fig.11: AFM image of pro seal treated enamel showing perikymata ridge and groove with obvious focal holes $(50 \times 50 \mu \mathrm{m})$.

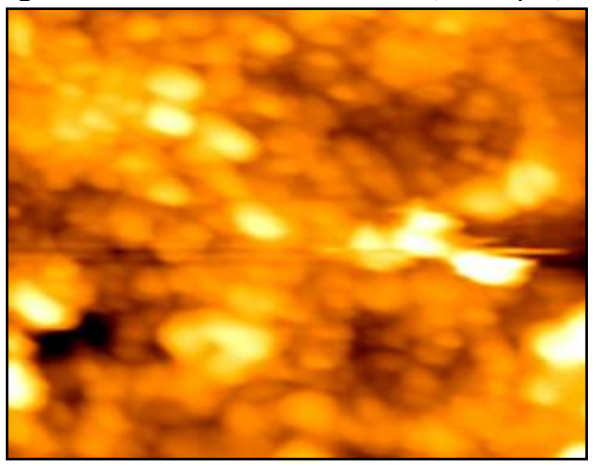

Fig.13: Tightly arranged crystals around conical depressions of pro seal treated group $(10 \times 10 \mu \mathrm{m})$. 
Egyptian

Orthodontic Journal

Table (1): Mean and SD. of roughness height and total surface area in all groups

\begin{tabular}{|l|c|c|}
\hline & Ra & SA \\
\hline control & $569.72 \pm 2.28$ & $2886.6 \pm 9.20$ \\
\hline varnish & $370.54 \pm 2.19$ & $2577.2 \pm 5.26$ \\
\hline u.sealant & $330.28 \pm 1.62$ & $2561.2 \pm 8.07$ \\
\hline pro seal & $307.24 \pm 2.58$ & $2507.2 \pm 7.08$ \\
\hline
\end{tabular}

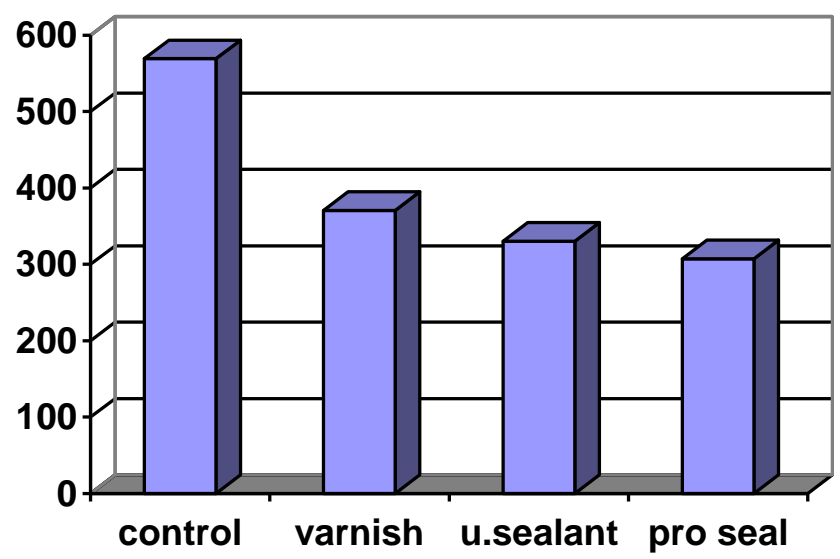

Fig.14: Histogram showing the mean roughness height in the different groups.

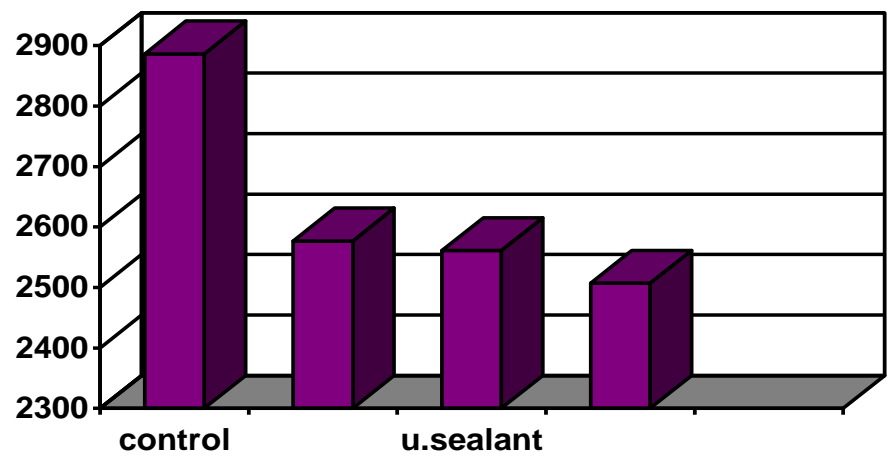

Fig.15: Histogram showing the mean surface area in the different groups 
Egyptian

Orthodontic Journal

Table (2): Analysis of ( $\mathrm{Ra})$ variance between and within the tested groups: $\mathrm{Ra}(\mu \mathrm{m})$

\begin{tabular}{|l|c|c|c|c|c|}
\hline & Sum of squares & Df & Mean Square & F & P-value \\
\hline $\begin{array}{l}\text { Between } \\
\text { Groups }\end{array}$ & 215073.169 & 3 & 71691.056 & 14862.100 & .000 \\
\hline Within Groups & 77.180 & 16 & 4.824 & & \\
\hline Total & $\mathbf{1 5 1 5 0 . 3 4 9}$ & $\mathbf{1 9}$ & & & \\
\hline
\end{tabular}

Table (3): Multiple comparisons using Post Hoc LSD test: Dependent Variable: Ra ( $\mu \mathrm{m})$

\begin{tabular}{|c|c|c|c|}
\hline (I) Group & (J) Group & Mean difference $\quad(\mathbf{I}-\mathbf{J})$ & P-Value \\
\hline \multirow[t]{3}{*}{ Control } & u. sealant & $239.4400 *$ & .000 \\
\hline & Pro seal & $262.4800 *$ & .000 \\
\hline & Varnish & $199.1800 *$ & .000 \\
\hline \multirow[t]{3}{*}{ u. sealant } & Control & $-239.4400 *$ & .000 \\
\hline & Pro seal & $23.0400 *$ & .000 \\
\hline & Varnish & $-40.2600 *$ & .000 \\
\hline \multirow[t]{3}{*}{ Pro seal } & Control & $-262.4800 *$ & .000 \\
\hline & u. sealant & $-239.4400 *$ & .000 \\
\hline & Varnish & $-63.3000 *$ & .000 \\
\hline \multirow[t]{3}{*}{ Varnish } & Control & $-199.1800^{*}$ & .000 \\
\hline & u. sealant & $40.2600 *$ & .000 \\
\hline & Pro seal & $63.3000 *$ & .000 \\
\hline
\end{tabular}


Table (4): Analysis of (SA) variance between and within the tested groups: $\mathrm{SA}\left(\mu \mathrm{m}^{2}\right)$

\begin{tabular}{|l|c|c|c|c|c|}
\hline & Sum of squares & Df & Mean Square & F & P-value \\
\hline Between Groups & 442037.350 & 3 & 147345.783 & 2586.148 & .000 \\
\hline Within Groups & 911.600 & 16 & 56.975 & & \\
\hline Total & $\mathbf{4 4 2 9 4 8 . 9 5 0}$ & $\mathbf{1 9}$ & & & \\
\hline
\end{tabular}

Table (5): Multiple comparisons using Post Hoc LSD test: Dependent Variable: SA $\left(\mu \mathrm{m}^{2}\right)$

\begin{tabular}{|c|c|c|c|}
\hline (I) Group & (J) Group & Mean difference $\quad$ (I-J) & P-Value \\
\hline \multirow[t]{3}{*}{ Control } & u. sealant & $309.4000 *$ & .000 \\
\hline & Pro seal & $379.4000 *$ & .000 \\
\hline & Varnish & $325.4000 *$ & .000 \\
\hline \multirow[t]{3}{*}{ u. sealant } & Control & $-309.4000 *$ & .000 \\
\hline & Pro seal & $70.0000 *$ & .000 \\
\hline & Varnish & $16.0000 *$ & .004 \\
\hline \multirow[t]{3}{*}{ Pro seal } & Control & $379.4000^{*}$ & .000 \\
\hline & u. sealant & $-70.0000 *$ & .000 \\
\hline & Varnish & $-54.0000 *$ & .000 \\
\hline \multirow[t]{3}{*}{ Varnish } & Control & $-325.4000 *$ & .000 \\
\hline & u. sealant & $-16.0000 *$ & .004 \\
\hline & Pro seal & $54.0000^{*}$ & .000 \\
\hline
\end{tabular}

The mean difference is significant at the 0.05 level. 


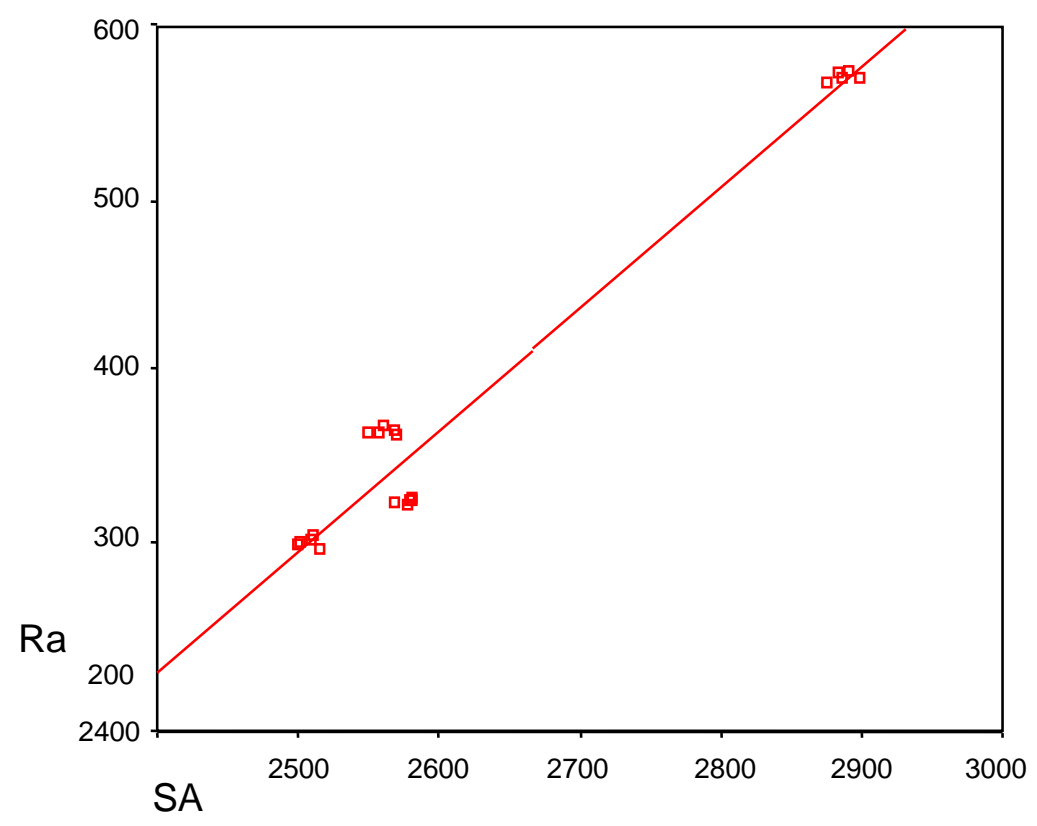

Fig. 16: Statistical correlation between roughness height and total surface ırea

\section{DISCUSSION}

Enamel demineralization has been demonstrated in vivo around orthodontic brackets after only one month ${ }^{(11)}$, so finding methods of reducing decalcification after orthodontic treatment is imperative. Sealing of enamel with sealant resin adjacent to orthodontic attachments, independent of patient compliance, would be extremely beneficial for clinical orthodontics to prevent demineralization ${ }^{(33)}$.

The first step in enamel dissolution is demineralization of the outer few micrometers of tissue due to penetration of acids, leading to loss of calcium and phosphate, which results in softening of the structure ${ }^{(36)}$. Accordingly, AFM was used in the current study for characterization of surface structures of enamel as it is very sensitive to the initial phases

of enamel dissolution even when the dissolution occur at a very low rate. AFM is ideally suited for biological imaging, since specimens do not need to be 
dehydrated, fixed stained or coated ${ }^{(37)}$. Moreover, it has an advantage over other ultra high vacuum measuring equipments as the specimen is imaged in its hydrated state in open air condition at room temperature. Thus enamel is not subjected to dehydration and high pressure difference that could affect topographical features. The principle of surface area calculation by AFM depends on the acquisition of 3-D surface height in Z- direction ${ }^{(38)}$.

The characterization of surface structures by tapping mode images of the present study revealed that Pro Seal treated enamel samples showed no destruction or loss of surface details. The focal holes that were seen at the enamel surface might be due to loss of enamel caps as a result of physiological wear of enamel surface due to function as described by Berkovitz et al ${ }^{(39)}$.

Statistical analysis showed that Pro Seal group had the least values of Ra $\&$ SA among all groups. This means that adding filler particles into the sealant improve and increase the thin layer being retained throughout treatment, and offer adequate resistance against wear in vivo. The smooth enamel surface with intact surface details (perikymata ridges and focal holes) denoted that Pro Seal could protect the enamel from acid penetration and preserve crystal shape and arrangement, which was typical to that described by Farima et al ${ }^{(40)}$ and Schaad et $\mathrm{al}^{(41)}$. The appearance of the crystal was similar to that described by Kirkham et al ${ }^{(42)}$. They reported that enamel proteins appeared to adopt the form of spheres closely resemble previously reported nanosphere structure in vitro ${ }^{(43)}$ and in vivo ${ }^{(44)}$. They suggested that these nanosheres represent an arrangement of original initiation sites for modulating matrix protein.

The results of the present work are in concomitant with $\mathrm{Hu}$ et al ${ }^{(3)}$ who evaluated the third molar teeth quantitavely by cross sectional micro hardness testing and reported that Pro Seal offers adequate resistance against wear during tooth brushing and essentially complete protection against decalcification in vitro. Cain et al ${ }^{(45)}$ found that Pro Seal exhibited statistically significant reduction in carious lesion initiation and progression in vitro.

The unfilled sealant group showed more protection to the enamel surface than varnish and control groups as indicated by its low values of Ra and SA and few localized areas of destruction. This result was different from that obtained by some previous studies ${ }^{(3,46,47)}$ which demonstrated that the demineralization lesion formed in unfilled sealant group was not different from the lesions in the untreated group. They attributed that to the presence of etched enamel underneath the sealant being exposed to the acid attack. 
On the other hand, the results of the present study are in accordance with the findings of Ceen and Gwinnett, ${ }^{(48)}$ Joseph et $\mathrm{al}^{(49)}$, Frazier et al. ${ }^{(50)}$, who reported that the protection afforded to the enamel did not just relay on retention of the superficial unfilled resin coverage. The enamel surface proved to be resistant to carious attack as long as the resin tags were present, which have been shown to extend from 80 to $170 \mu \mathrm{m}$ into the enamel surface, even after mechanical removal of the sealant.

The present study revealed that varnish group presented destructed enamel surface in accordance with previous reports suggesting that varnish slowed down the progress of demineralization but did not completely inhibit the formation of enamel lesions. A high bacterial challenge can not be completely overcame by fluoride varnish ${ }^{(51)}$. The varnish group presented high surface roughness compared to the unfilled sealant group in accordance with Gaballa ${ }^{(52)}$, this could be attributed to deposition of calcium fluoride particles on the enamel surface.

The high surface irregularity, defective crystal appearance and wide inter-crystalline spaces that were reported in the control and varnish groups of the current study were suggested to reflect affection of the organic phase in addition to dissolution of enamel crystals ${ }^{(51)}$.

\section{Conclusions and Recommendations:}

* Atomic force microscope is a useful tool to image the topography of enamel surface at high resolution and allow the measurement of nanomechanical properties of enamel.

* The use of light-cured filled sealant (Pro Seal) in orthodontic patients with brackets resulted in significantly low mean of roughness height and total surface area with no signs of surface demineralization or loss of surface details.

* Pro Seal can be considered the most efficient preventive method in reducing enamel demineralization around orthodontic brackets.

\section{REFERENCES}

1. Zimmer W.B., Rollwinkel Y. Assessing patient-specific decalcification risk in fixed orthodontic treatment and its impact on prophylactic procedures. Am J Orthod Dentofacial Orthop. 2004; 126:318- 324.

2. Chadwick LB, Roy J, Knex J, Treasure TE. The effect of topical fluorides on decalcifications of patients with fixed orthodontic appliance: A systemic review. Am J Orthod Dentofacial Orthop. 2005; 128:301-306. 
3. Hu W, Featherstone JD. Prevention of enamel demineralization: an invitro study using light cured filled sealant. Am J Orthod Dentofacia Orthop. 2005; 128:592-600.

4. Gorelick L, Geiger M, Gwinnet AJ. Incidence of white spot formation after bonding and banding. Am J Orthod. 1982; 81:93-98.

5. Ögaared B. Prevalence of white spot lesions in 19 years old: a study on untreated and orthodontically treated persons 5 years after treatment. Am J Orthod Dentofacial Orthop. 1989; 96:423- 427.

6. Basdra EK, Huber H, Komposch G. Fluoride Release from orthodontic bonding agents alters enamel surface and inhibits enamel demineralization in vitro. Am J Orthod Dentofacial Orthop 1999; 11:205- 214.

7. Schwaninger B, Vickers- Schwaninger N. Developing an effective oral hygiene program for the orthodontic patients: review rationale, and recommendations. Am J Orthod. 1979; 75:474- 482.

8. Ramaglia L. Sbordone L, Ciaglia RN. Barone A, Martina R. A clinical comparison of the efficacy and efficiency of two professional prophylaxis procedures in orthodontic patients. Eur J Orthod. 1999; 21:423-428.

9. Anderson GB, Bowden J, Morrison EC, Caffesse RG,. Clinical effects of chlorhexidine mouth washes on patients undergoing orthodontic treatment. Am J Orthod Dentofacial Orthop. 1997; 111:606- 612.

10. Zachrisson BU. Fluoride application procedures in orthodontic practice, current concepts. Angle Orthod. 1975; 45:72-81.

11. O'Reilly MM. Featherstone JDB. Demineralization and remineralization around orthodontic appliances: an in vivo study. Am J Orthod Dentofacial Orthop. 1987; 92:33-40.

12. Ten Cate JM. Current concepts on the theories of the mechanism of action of fluoride. Acta Odontol Scand. 1999; 57:325- 329.

13. Ögaard B, Rolla G, Arends J. Orthodontic appliance and enamel demineralization. Part 1, lesion development. Am J Orthod Dentofacial Orthop. 1988; 94:68- 73.

14. Stratemann MW, Shannon IL. Control of decalcification in orthodontic patients by daily self-administered application of a water-free $0.4 \%$ stannous fluoride gel. Am J Orthod. 1974; 66:273-279.

15. Ögaard B, Rolla G, Arends J, Ten Care JM. Orthodontic appliances and enamel demineralization. Part 2, prevention and treatment of lesions. Am J Orthod Dentofacial Orthop. 1988; 94:123- 128. 
16. Adriaens ML, Dermaut LR, Verbeeck MH. The use of "Fluor Protector" a fluoride varnish as a caries prevention method under orthodontic molar bands. Eur J Orthod. 1990; 12: 316-319.

17. Geiger AM, Gerolick L, Gwinnett AJ, Benson BJ. Reducing white spot lesions in orthodontic populations with fluoride rinsing. Am J Orthod Dentofacial Orthop. 1992; 101:403- 407.

18. Rezk- Lega F, Ögaard B. Tensile bond force of glass ionomer cement in direct bonding of orthodontic brackets: an in vitro comparative study. Am J Orthod Dentofacial Orthop. 1991; 104:47- 52.

19. Compton Am., Meyers CE, Hondrum So, Lorton L. Comparison of the shear bond strength of a light-cured glass ionomer and chemically cured glass ionomer for use as an orthodontic bonding agent. Am J Orthod Dentofacial Orthop. 1992; 101:138- 144.

20. Mc Neil CJ, Wiltshire WA. Dawes C, Lavelle CL. Fluoride release from new light-cured orthodontic bonding agents. Am J Orthod Dentofacial Orthop. 2001; 120:392- 397.

21. Whealer AW. Foley TF, Mamandras A. Comparison of fluoride release protocols for in-vitro testing of 3 orthodontic adhesives. Am J Orthod Dentofacial Orthop. 2002;121:301-309.

22. Schmit JL, Staley RN, Wefel JS, Kanellis M, Jakobson JR, Keenan PJ. Effect of fluoride varnish on demineralization adjacent to brackects bonded with RMGI. Am J Orthod Dentofacial Orthop. 2002; 122:125- 134.

23. Gaworski M, Weinstein M, Borislow AJ. Braitman: LE. Decalcification and bond failure: a comparison of glass ionomer cement or a resin adhesive. Angle Orthod. 1999;69:65-70.

24. Millett DT, Nunn JH, Welbury RR, Gordon PH. Decalcification in relation to brackets bonded with glass ionomer cement or a resin adhesive. Angle Orthod. 1999;116:518-522.

25. Gorton J, Featherstone JDB. In vivo inhibition of demineralization around orthodontic brackets. Am J Orthod Dentofacial Orthop. 2003; 123:10- 14

26. Pascotto RC, Navarro MF, Filho LC, Cury JA. In vivo effect of a resin modified glass ionomer cement on enamel demineralization around orthodontic brackets. Am J Orthod Dentofacial Orthop. 2004; 125:36-41.

27. Zachrisson BU. Causes and prevention of injuries to teeth and supporting structures during orthodontic treatment. Am J Orthod. 1976; 69:285- 300. 
28. Tillery TJ. Hembree JH. Weber FN. Preventing enamel decalcification during orthodontic treatment. Am J Orthod. 1976; 70:435- 439.

29. Zachrisson BU, Heimgard E. Ruyter IE, Mjor IA. Problems with sealants for bracket bonding. Am J Orthod. 1979; 75:64- 69.

30. Cee RF, Gwinnett AJ. Microscopic evaluation of the thickness of sealants used in orthodontic bonding. Am J Orthod. 1980; 78:623- 629.

31. Joseph VP, Rossouw RE, Basson NJ. Some "Sealants" seal- a scanning electron microscopy (SEM) investigation. Am J Orthod Dentofacial Orthop. 1994; 105:362-368.

32. Frazier MC, Sothard TE, Doster PM. Prevention of enamel demineralization during orthodontic treatment: an in vitro study using pit and fissure sealants. Am J Orthod Dentofacial Orthop 1996; 110: 459-465.

33. Wenderoth CJ, Weinstein M, Borislow AJ. Effectiveness of a fluoride resin in reducing decalcification during orthodontic treatment. Am J Orthod Dentofacial Orthop. 1999; 166: 629- 634.

34. Paschos E, Okuka S, Ilie N, Nuth Kc, Hickel R, Rudzki-Janson I. Investigation of shear-peel bond strength of orthodontic brackets on enamel after using Pro seal. Am J Orthod Dentofacial Orthop 2006;67:196-206.

35. Bishara SE, Oonsombat C, Soliman MM, Warren J. Effect of using a new protective sealant on the bond strength of orthodontic brackets. Angle Orthod. 2005;75:243-246

36. Barbour ME, Parker DM, Allen GC, Jandt KD. Enamel dissolution in citric acid as a function of calcium and phosphate concentrations and degree of saturation with respect to hydroxyl apatite. Eur J Oral SCie.2003; 111:428-433.

37. Ikai A. STM and AFM of bio-organic molecules and structures. Surf Sci Rep .1996;26:263-332

38. Habelitz S, Maslall SJ, Marsall CW, Baloccch M. Mechanical properties of human dental enamel on the nanoscale. Arch Oral Biol. 2001; 46:173-183

39. Berkovitz BK, Holand GR, Maxham BJ. Oral anatomy, Histology and Embryology. $3^{\text {rd }}$ ed. Edinburgh, London, NY. Mosby inc. 2002; 112-113.

40. Farima M, Schemmel A, Weissmuller G, Cruz R, Kachar B,Bisch PM. Atomic force microscopic study of the tooth surfaces. J Struct.Biol.1999; 125:39-49.

41. Schaad P, Paris E, cuisinier FJ, voegel JC. Atomic force microscopic study of human tooth enamel surface. Scanning Microsc.1993; 4:1149-152. 
42. Kirkham J, Zhang j, Brookers SJ, Shore RC, Wood SR, Smith DA, Wallwork ML, Ryu OH, Robinson C. Evidence for charge domains of developing Enamel crystal surfaces. J Dent Res. 2000; 79:1943-1947.

43. Fincham AG, Moradian-Oldak J, Simmer JP,Sart P, Lau EC, Diekwisch T, et al. Self-assembly of a recombinant amelogenin protein generates supramolecular structures. J Struct Biol 1994; 112:103-109.

44. Robinson C, Yamamoto K, Connell SD, Kirkham J, Nakagaki H, Smith AD. Surface pk of enamel crystals: an atomic force microscopy study of human and rat enamel.eur J oral Sci.2006;114:99-104.

45. Cain K, Hick J, English J, Flaitz C, Powers JM, Rives T. In vitro enamel caries formation and orthodontic bonding agents. Am J Dent 2006;19:187-92.

46. Banks PA, Richmond S. Enamel sealants: a clinical evaluation of their value during fixed appliance therapy. Eur J Orthod 1994; 16: 19-25.

47. Wenderoth CJ, Weinslein J, Borislow AJ. Effectiveness of a fluoridereleasing sealant in reducing decalcification during orthodontic treatment. Am J Orthod Dentofacial Orthop. 1999; 166: 62 9-634.

48. Ceen RF, Gwinnett AJ. Microscopic evaluation of the thickness of sealants used in orthodontic bonding. Am J Orthod. 1980; 78: 623-9.

49. Joseph VP Rossouw PE, Basson NJ. Do sealants seal? An SEM investigation. J C O 1992; 26: 141-4.

50. Frazier MC, Southward TE Dosler PM. Prevention of enamel demineralization during orthodontic treatment: An in vitro study using pit and fissure sealants. Am J Orthod Dentofac. Orthop. 1996; 110: 459-65.

51. Todd MA, Slaley RN, Kanellis MJ, Donly KJ, Wefel JS. Effect of fluoride varnish on demineralization adjacent to orthodontic brackets. Am J Orthod Dentofacial Orthop.1999;116:159-67.

52. Gaballa SM., Ghobashy SA. Effect of fluoride varnish versus light-cured resin sealants on enamel demineralization in vivo. Egp Orthd J, 2002; 22:19-31. 